\title{
Reply to: Improving normalized hurricane damages
}

\author{
R. Pielke Jr(1凶, D. Collins ${ }^{2}$, R. Crompton ${ }^{3}$, P. Klotzbach ${ }^{4}$, R. Musulin ${ }^{5}$ and J. Weinkle ${ }^{6}$
}

REPLYING TO A. B. Martinez Nature Sustainability https://doi.org/10.1038/s41893-020-0550-5 (2020)

We welcome the work of Martinez ${ }^{1}$, seeking to extend and improve the continental US hurricane loss normalizations of our paper ${ }^{2}$. There are of course many legitimate approaches to normalizing historical loss data to a common base year. In principle, the proposal by Martinez to add an additional factor accounting for changes in building costs makes logical sense. And we agree that the effectiveness of any such modification to a normalization can be evaluated quantitatively by comparing with an independent climatological record.

We agree with Martinez that there is evidence to suggest that normalization results for the earlier part of the twentieth century may underestimate the potential for contemporary losses ${ }^{2}$. We also agree that the use of price deflators more closely associated with hurricane losses may to improve normalization results. With those major points of agreement, we urge three methodological cautions.

First, Martinez uses one widely known building price deflator in the Case-Shiller index ${ }^{3}$. However, just as there are multiple, valid approaches to normalization, there are also multiple, valid approaches to estimating building price indices (for example, see ref. ${ }^{4}$ ). The Case-Shiller index is based on estimates of wages dating to 1915 paid to "bricklayers, carpenters, and structural ironworkers" in 20 cities, most of which do not experience hurricanes ${ }^{3}$. A more robust treatment of price indices would consider more than one index.

Second, Martinez applies the building price index to the entirety of losses. This is appropriate to the degree that losses result from residential building damage. However, commercial property losses, public infrastructure losses, inventory, commercial goods, household wealth, automobiles and other factors comprise a substantial portion of hurricane losses and would not be appropriately represented by a residential housing price index.

Finally, we note that that Martinez indicates (see the supplementary information in ref. ${ }^{1}$ ) that the use of the Case-Shiller price index adjustment does not unequivocally improve on the statistical comparison between an unbiased climatological record and the normalizations of our paper ${ }^{2}$. In their supplementary table $1^{1}$,
Martinez clearly shows that our normalizations outperform their own, whereas supplementary table $3^{1}$ indicates that we may, to some degree, have had a low bias compared with one set of catastrophe model estimates, but it also indicates that Martinez may exhibit a corresponding high bias.

In conclusion, for hurricanes of the early twentieth century, we are in agreement with Martinez that our results ${ }^{2}$ may indeed underestimate normalized losses. However, we also believe that the modified methodology proposed by Martinez overestimates these same losses. It is reasonable to conclude that a more accurate normalization would fall between these estimates.

Received: 23 July 2019; Accepted: 6 May 2020;

Published online: 8 June 2020

\section{References}

1. Martinez, A. B. Improving normalized hurricane damages. Nat. Sustain. https://doi.org/10.1038/s41893-020-0550-5 (2020).

2. Weinkle, J. et al. Normalized hurricane damage in the continental United States 1900-2017. Nat. Sustain. 1, 808-813 (2018).

3. Shiller, R. J. Irrational Exuberance 3rd edn (Princeton Univ. Press, 2015).

4. Nagaraja, C. H., Brown, L. D. \& Wachter, S. M. House Price Index Methodology (Univ. Pennsylvania, 2010); https://repository.upenn.edu/ statistics_papers/145

\section{Author contributions}

All authors contributed to the preparation of this letter, led by R.P.

\section{Competing interests}

The authors declare no competing interests.

\section{Additional information}

Correspondence and requests for materials should be addressed to R.P.

Reprints and permissions information is available at www.nature.com/reprints.

Publisher's note Springer Nature remains neutral with regard to jurisdictional claims in published maps and institutional affiliations.

(C) The Author(s), under exclusive licence to Springer Nature Limited 2020 